\title{
Editorial
}

\section{Escritas de artista e outras proposições}

O Dossiê Escritas de artista e outras proposições reúne investigações, proposições e reflexões em torno da escrita, da leitura e da escuta como processos, práticas, procedimentos e situações que catalisam, inscrevem e/ou dão corpo a projetos artísticos e seus desdobramentos, bem como, ativam questões e operações nesses processos e práticas. Deste modo, esta edição apresenta um conjunto singular de trabalhos que propõem pensarmos sobre e a partir de modulações propostas por escritas de artista e suas possibilidades diversas de inscrição.

Proposições e investigações que envolvem a "escrita assêmica", a "leitura como respiração" (entre escrita e escuta), "experimentações tridimensionais da escrita", textos que só existem desde seus gestos, estados e dimensões corporais e sonoras, textos-obras, textos-dobras, escritas-relatos e anotações de/em processo, textos performativos, ativadores e indicadores de espaços e tempos, textos geradores de brechas, erosões e outras escalas, em diversos percursos e contextos, seja da língua, do corpo, da cidade, da paisagem, da escuta ou da voz. Propõe-se também abordar articulações heterogêneas entre texto e som no campo da arte contemporânea e suas intersecções e/ou reverberações em outros contextos, numa relação com outros espaços da arte, com práticas da publicação de artista, assim como, com processos de escrita em propostas de pesquisas em arte.

O Dossiê apresenta ainda a proposta de uma Exposição na Revista Palíndromo, com curadoria das organizadoras, Raquel Stolf e Regina Melim, tendo a participação de vinte e sete artistas convidados/as - Daniela Avelar, Pedro Franz, Ivana Vollaro, Júlia Rocha, Claudia Zimmer, Iam Campigotto, Kamilla Nunes, Aline Natureza, Sofia Brito, Daniela Castro, Julia Amaral, Kim Coimbra, Manolo Carlos, Lívia Aquino, Patrícia Galelli, Traplev, Luana Navarro, Maíra Dietrich, Telma Scherer, Matheus de Simone, Yuri Bruscky, Marcela Lucatelli, Gianluca Elia, Henrique Iwao, Bruno Mendonça, Marion Velasco, Renata Roman -, e projeto gráfico por Anna Stolf.

Inicia-se com o texto de Belén Gache, intitulado Consideraciones sobre la escritura asémica: el caso de Mirtha Dermisache, em que a autora aborda a escrita da artista argentina Mirtha Dermisache e seus trabalhos em torno da "escrita assêmica" como forma de resistir aos significados atribuídos através de uma linguagem que define, nomeia, diferencia, ordena e estabelece parâmetros no nível social. Belén Gache parte da hipótese de que Mirtha Dermisache registrou em sua obra a incompreensão e assimetria de códigos em uma conturbada sociedade argentina durante a ditadura. 
Desse modo, sua escrita com "sinais ilegíveis" apontava a falta de um código compartilhado com essa comunidade minada por discursos de censura, autocensura e medo.

Já em QUANDO EU LEIO, RESPIRO, Aline Dias investiga a produção da artista Roni Horn, focando nos "percursos e contágios entre arte contemporânea e práticas de leitura e escrita". A autora parte de uma relação entre desenho e respiração, proposta por Roni Horn, "enquanto prática vital, corporal, continuada e ancorada no presente", estendendo esta dimensão à escrita-leitura da artista. São abordados "textos como margens e/ou travessias em seus trabalhos; títulos e notas de rodapé que constituem o trabalho artístico em indissociável conexão com imagens fotográficas (You are the weather, Still water e Another water); e trabalhos que dão corpo escultórico e/ou gráfico a sua leitura das obras de Simone Weill, Franz Kafka, Clarice Lispector e Emily Dickinson."

Annelise Estrella, em A poética pública de Hélio Oiticica: 19 obras inespecíficas, aborda a produção de textos do artista brasileiro Hélio Oiticica, que "usou a palavra e o gesto da escrita para organizar e apresentar seu trabalho ao mundo." A autora discorreu sobre "a poética pública de Oiticica concebida no Rio de Janeiro entre 1965 e 1968, cuja composição se dá por 19 textos inscritos em Parangolés, Bólides e bandeira". Realizou a análise de Parangolés com inscrições e a articulação entre seus aspectos visuais e textuais - Parangolé P11 Capa 7 (1966), com "Estamos Famintos", e o Parangolé P18 Capa 16 (1968), com "Sexo e violência: eis o que me agrada". Salientou ainda "a noção de 'frutos estranhos', de Florencia Garramuño, que designa objetos artísticos de difícil classificação, híbridos."

Em ENTRE NA ESCRITA: UMA QUESTÃO DE DESVIO Letícia Bertagna reflete sobre a escrita que se articula com a pesquisa artística no âmbito acadêmico, seus procedimentos e os modos possíveis de enunciação e de relação entre diferentes registros de exercícios poéticos. Uma escrita, segundo ela, "paradoxal e às voltas com os meandros da obscuridade e da clareza, dedicada a colocar em questão a própria linguagem". Assim, como uma espécie de princípio desordenado, fazendo uso do desvio e da deriva como apostas de uma metodologia, Letícia Bertagna busca tramar uma escrita capaz de promover a experiência e o diálogo com os movimentos oblíquos do processo artístico.

No ensaio E_CRITOR_S, Fabio Morais aborda as diferentes formas que a escrita adota frente às materialidades e espaços da arte, analisando algumas obras de arte contemporânea que têm o texto verbal como eixo e uma "experimentação tridimensional da escrita". Desse modo, o autor propõe uma espécie de "tradução de um texto-obra" através de um ensaio-curadoria que "mimetiza uma deriva por um espaço expositivo", registrando também articulações de pensamentos ou narrativas no próprio tecido do ensaio.

Em Res pondibilidade: uma escrita de mirada, Elilson apresenta um texto ex- 
perimental como um "compilado de escutas" ou "uma experimentação em torno do caminhar - decidir - abordar - perguntar - escutar como um ciclo deflagrador de uma escrita que quer oralizar-se." Numa ação performativa, seu texto escuta parágrafos inscritos por pessoas nas ruas durante horas de caminhada atravessado pelas questões: Como tornar a escrita menos grafocêntrica? Como liberar a palavra do peso arquivístico e da doutrina documental? Como tornar o escrever uma prática de ação coletiva?

Silfarlem Oliveira e Letras Escrevedoras apresentam CLASSIFICADOS, que numa versão em formato dobrável integra também sua tese de doutorado, intitulada "o mesmo desafia o mesmo", desenvolvida junto ao Programa de Pós-Graduação em Artes Visuais da Universidade do Estado de Santa Catarina. A partir de proposições de "letras escrevedoras da biblioteca mesmo" para "letras leitoras", que farão o intercruzamento, "fisgando uma parte aqui e correlacionando ela com outra de lá e assim sucessivamente", o texto apresenta cinco segmentos denominados "fragmentos mesmo", "fragmentos tautológicos", "fragmentos repetições", "fragmentos fragmentos", "fragmentos contextuais" e "fragmentos ficções". Adverte-se também sobre a presença no escrito de "palavras ausentes " ", " ", " " e igualmente traços de linguagem não-verbal advindos dos corpos."

\section{Em DESAPROPRIO A HORA AO REDOR DESTE ARTIGO: notações pessoais sobre} proposições de Guilherme Vaz, Daniel Leão aborda três proposições artísticas de Guilherme Vaz entre 1969 e 1970. A primeira delas apresentada no Salão da Bússola no Museu de Arte Moderna do Rio de Janeiro, seguindo com a mostra sequencial Agnes Dei na Petite Galerie do Rio de Janeiro e por fim a proposição para a exposição Information no Museu de Arte Moderna de Nova York. São trabalhos fortemente marcados por encontros e contágios com Artur Barrio, Thereza Simões, Nelson Pereira dos Santos e Frederico Morais, e que se dão através de palavras em três modos distintos: em performance realizada pelo próprio artista, em escritos através de pequenos bilhetes afixados na galeria ou em instruções reproduzidas por um alto-falante.

\section{Em VOZ VIVA ESCUTA CANSADA: MODOS DE FAZER E PENSAR UMA ESCRITA} COMPULSADA, Priscila Costa Oliveira apresenta um fragmento de sua pesquisa de doutorado em andamento, intitulada "Conversas sobre conversas: fala e escuta nas práticas artísticas contemporâneas", desenvolvida junto ao Programa de Pós-Graduação em Artes Visuais da Universidade do Estado de Santa Catarina. O texto investiga e propõe "modos de pensar e fazer uma escrita compulsada" a partir de alguns trabalhos da autora -"Disparadores de conversação"; "Plantando escuta"; "Orelha Dormente / Escuta cansada" e "podcast VERSAR". São assinalados processos e reflexões a partir de "uma arte verbal, sonora, pública e participativa, que considere a especificidades da vocalização e da escuta a partir de experimentações e exercícios que possibilitam um trânsito entre voz e escrita viva."

Daniela Avellar, no texto DA PARTITURA À AÇÃO, aborda as propostas e experiências Fluxus, as concepções de George Brecht e John Cage, bem como, a utilização da forma partitura por artistas dos anos 60, numa articulação com a linguagem e sua performatividade. Ressalta-se que quando a partitura passa a ser uma inscrição sem objetivos 
substancialmente representacionais, ela assume uma direção mais indicativa de ações, sendo que "tanto as partituras-acontecimento como os procedimentos 'cageanos' se utilizam de uma temporalidade performativa em relação à escrita e à leitura, assim como em relação à escuta."

Em VIAGEM AO SENSíVEL DA TERRA, Camila Proto apresenta um relato processual que busca investigar um tensionamento da maneira como percebemos o mundo, e de "como fazemos mundo hoje." Aborda-se a escrita como um encontro, sugerindo-se "deslocar os modos de percepção não somente do entorno, mas de si mesmo: o que vejo em mim quando de frente à uma paisagem?" Ou ainda, como pensar e perceber "as intenções e expressões de uma paisagem cambiante, em constante transformação"?

Em Padrões Infecciosos, Marina Dúbia apresenta um breve ensaio a partir de uma pergunta que atravessa o texto - "como você se amplifica?" - (proposta pela residência Contágio 3x3, em abril de 2017, no Sesc Pinheiros), sugerindo uma escrita movida pelo que a artista indica como "ferramentas de direção afetiva".

Já Keyla Sobral, em VIAGEM DE K. - Notas sobre uma viagem inventada apresenta um ensaio a partir de um recorte de um caderno de artista, que integra sua pesquisa de doutorado junto ao Programa de Pós-Graduação em Artes Visuais da Universidade Federal do Pará. No ensaio, a autora apresenta experimentações entre a literatura e as artes visuais, percorrendo "um território inventado onde há um cruzamento de fronteiras entre as linguagens". A personagem K. é "uma artista-viajante, onde sua história é contada por meio de imagens, palavras e outros processos artísticos."

\section{Em TRADIZENDO EXÚ: GALINHA DE AFOGAR PATOS: ESCREVIVÊNCIAS DO (N)}

OVO, Carolina Primeira, Vermelho e Way Puri propõem um texto que investiga e pratica uma "escrita-gesto, um artigo-rito, um ensaio-feitiço, um (de vários) falar-comer, um escrever-viver, um ler-cuspir, um escutar-chocar." Numa escrita-gesto que "joga com as palavras de debret em sua 'Viagem pitoresca e histórica ao Brasil'", propõe-se uma "escrita de criação, cocriação y autocriação que nos reinscreve. somos aqui três corpos capazes novamente de assumir a primeira pessoa, do plural. corpos-pensamentos-selvagens-indóceis ancestrais, corpos que abriram caminho cortando mato y arrancando tocos em meio a academia y a arte. os (de)(re)tratados que invadem a missão. corpos dispostos aos riscos y liberdades do experimento".

A capa da revista apresenta o registro do trabalho $1+0$, do artista Fabio Morais, fotografado por Edouard Fraipont, na exposição individual çonoplaztía, realizada em novembro de 2018 na Galeria Vermelho, em São Paulo. A capa teve o projeto gráfico de Claudio Moreira. 
As organizadoras do Dossiê Escritas de artista e outras proposições agradecem a contribuição generosa de todas/os autoras/es em dispor de seus trabalhos para a publicação, e desejam uma experiência instigante de leitura e escuta.

Raquel Stolf (PPGAV/UDESC)

Regina Melim (PPGAV/UDESC) 